\title{
Incentive Regulation of Electricity and Gas Networks in the UK From RIIO-1 to RIIO-2
}

\author{
Jamasb, Tooraj
}

Document Version

Final published version

\section{Publication date:}

2020

\section{License \\ Unspecified}

Citation for published version (APA):

Jamasb, T. (2020). Incentive Regulation of Electricity and Gas Networks in the UK: From RIIO-1 to RIIO-2.

Department of Economics. Copenhagen Business School. Working Paper / Department of Economics.

Copenhagen Business School No. 1-2020CSEI Working Paper No. 1-2020

Link to publication in CBS Research Portal

\section{General rights}

Copyright and moral rights for the publications made accessible in the public portal are retained by the authors and/or other copyright owners and it is a condition of accessing publications that users recognise and abide by the legal requirements associated with these rights.

\section{Take down policy}

If you believe that this document breaches copyright please contact us (research.lib@cbs.dk) providing details, and we will remove access to the work immediately and investigate your claim. 
Copenhagen

Business School

HANDELSH ØJSKOLEN

\section{Department of Economics}

Copenhagen Business School

Working paper 1-2020

\begin{tabular}{|} 
Incentive Regulation of \\
Electricity and Gas Networks in \\
the UK: \\
From RIIO-1 to RIIO-2 \\
Tooraj Jamasb
\end{tabular}

Department of Economics - Porcelænshaven 16A, 1. DK-2000 Frederiksberg 


\section{WORKINIG PAPER}

Copenhagen School of Energy Infrastructure | CSEl

\section{Incentive Regulation of Electricity and Gas Networks in the UK: From RIIO-1 to RIIO-2}

Tooraj Jamasb

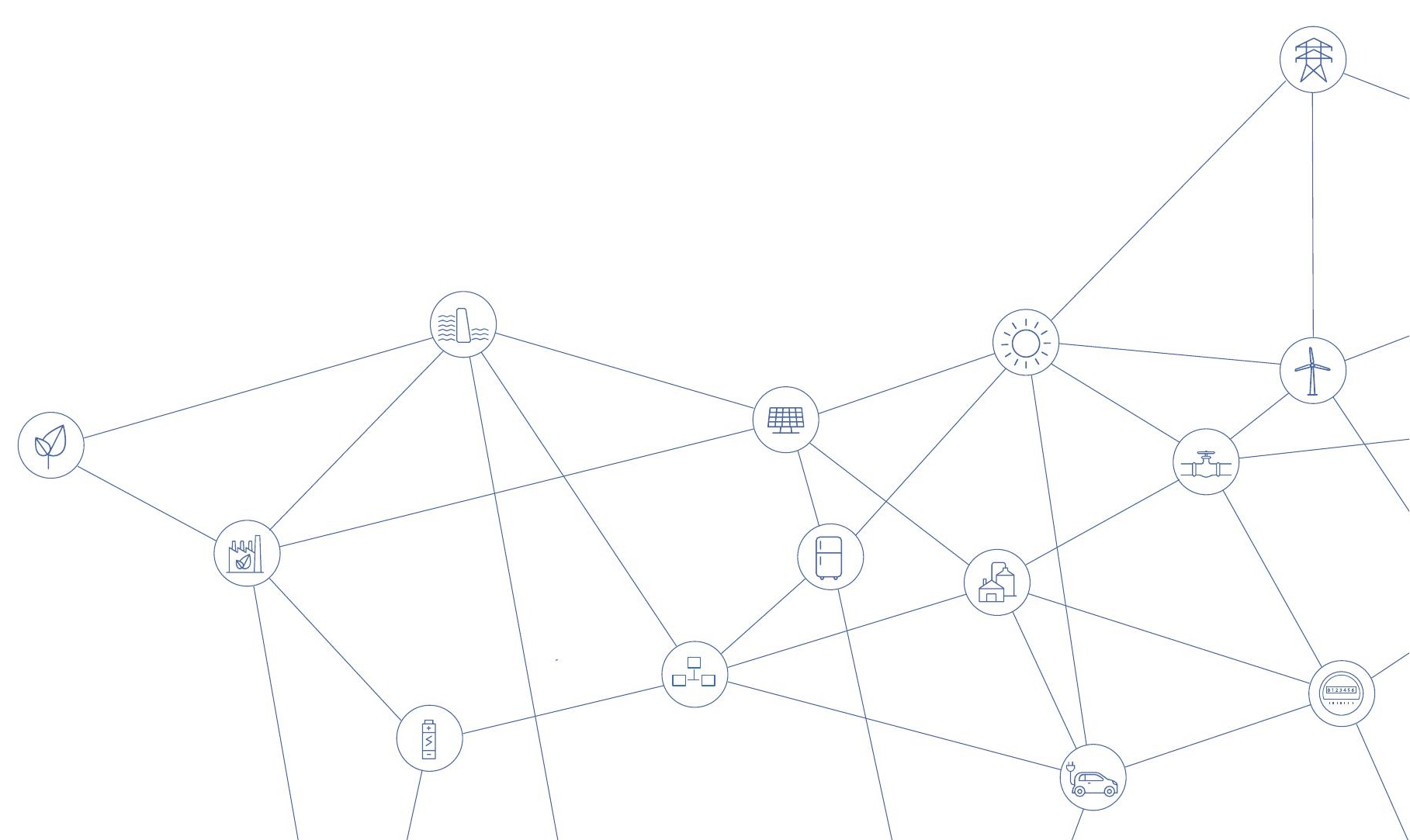




\title{
Incentive Regulation of Electricity and Gas Networks in the UK: From RIIO-1 to RIIO-2
}

\author{
Tooraj Jamasb \\ Copenhagen School of Energy Infrastructure (CSEI), \\ Department of Economics, Copenhagen Business School
}

6 February 2020

\begin{abstract}
The regulatory and operating context of energy networks is dynamic and constantly evolving. Achieving a multitude of economic, environmental, social and policy objectives is a challenging task for the sector regulators. In 2010, the UK energy regulator Ofgem replaced its approach to energy network price control and incentive regulation with a Revenue-Incentive-Innovation-Output (RIIO-1) model. This paper reviews the incentive areas that influence the performance of the next version of the model (RIIO-2). Guided by the principals of regulatory economics and evidence in the literature, we discuss key aspects of the regulation model that be revised by the regulator. The lessons of experience from the RIIO models are also relevant for regulators in other countries and can inform their design of incentive regulation of energy networks.
\end{abstract}

Key words: Energy networks, incentive regulation, rate of return, cost of capital, benefit sharing, menu of options.

JEL Classifications: K23, K43, L51, L52.

\section{Acknowledgment:}

The author acknowledges financial support for this work from Ofgem. The paper has benefited from extensive discussions and many useful comments received from members of the staff for which the author is most grateful. The views expressed in the paper are solely those of the author and do not represent those of Ofgem. The responsibility for all factual and substantive errors rests with the author.

\section{Correspondence:}

Tooraj Jamasb, Copenhagen School of Energy Infrastructure (CSEI), Department of Economics, Copenhagen Business School, Porcelaenshaven 16A | PH16A-2.70, 2000 Frederiksberg, Denmark, Phone: +45 38152223, Email: tj.eco@cbs.dk 


\section{Background}

During the initial post-liberalisation years in the UK, the regulation of electricity and gas networks was mainly focused on improving cost efficiency, quality of service, and network energy losses. By the 2000s, the policy and technological landscape had evolved and brought about new regulatory possibilities and priorities. The UK energy sector regulator Ofgem faced challenges related to smart meters and networks, distributed generation, access charging methodologies, new business models, electric storage technologies, environmental and sustainability concerns, and fuel poverty. This meant that the regulation of energy networks would have implications beyond the networks and for the wider energy systems as well as their customers and the wider society.

In addition, other subtle but important developments are also taking place. First, in recent years, the demand for energy in many developed economies has been flat or slightly declining. Second, new technologies and investments for building the future smart grids make the networks more capital intensive. Third, the economy and consumer lifestyle are increasingly dependent on new and high-value usages of energy services requiring reliable networks. As a result, the value of the energy used by consumers is increasing. At the same time, post-reform structural changes and technological progress in the sector constantly require revisiting allocation of property rights, information asymmetry, and incentive properties of regulation in the sector (Glachant, 2012).

As part of the preparations for the second periodic output-based network price controls (RIIO-2) of the gas and electricity networks, the UK regulator (Ofgem) has revisited the regulatory framework of the RIIO-1 model. The first model (RIIO-1) marked a transition from cost-efficiency regulation to an output-oriented focus and framework (Ofgem, 2010). The regulatory period of RIIO-1 ends in 2020 and Ofgem, as part of preparations for RIIO-2, is considering a set of modifications to the RIIO-2 price controls. These changes can affect the incentives, conduct, and output delivery of the energy networks in the short- and long-run. This paper aims to present an economic assessment of the incentive properties of the key proposed changes to energy network price controls under the RIIO-2 model. 
The motivation for revising the incentive mechanisms of the next price control of energy networks under the RIIO-2 framework is evident in Ofgem's Decision Document: “When returns fall well outside ex ante expectations, particularly across all companies in a sector, we think it is more likely due to network companies exploiting information asymmetry, forecasting errors, or due to a poorly calibrated price control mechanism." (Ofgme, 2019).

We examine the likely changes in the output-based RIIO-2 model for gas and electricity transmission and distribution network price control in the UK. The expected changes can include: (i) Removing the Information Quality Incentive (IQI) scheme and replacing this with a Business Plan Incentive (BPI) scheme, (ii) adjusting the Totex Incentive Mechanism (TIM) and applying lower Sharing Factors to cost savings, (iii) introducing a Blended Sharing Mechanism to costs with low or high regulatory confidence levels, and (iv) introducing a Return (on equity, RORE) Adjustment Mechanism (RAM).

Section 2 reviews the evolution of utility regulation. Section 3 discusses the economic and incentive aspects of the length of regulatory lag. Section 4 discusses the return adjustment mechanism. Section 5 discusses information asymmetry and incentive mechanisms. Section 6 assesses profit sharing mechanism in RIIO-2 and its link to the allowed cost of equity. Section 7 considers targeted incentives and their efficiency. Section 8 summarises and concludes. Appendix 1 outlines the main areas of change and the rationale for revising the RIIO-2 model.

\section{Milestones in the Evolution of Utility Regulation}

Historically, regulation of network utilities has been justified by the absence of markets or public ownership. In other words, economic regulation has been the dominant approach to overseeing the structure and conduct of vertically integrated private natural monopoly utilities and protecting the interests of consumers. It was, therefore, not a coincidence that independent economic regulation and rate of return (ROR) regimes were the main mode of regulation of investor-owned utilities in the US. For decades, the ROR regulation constituted the main model for economic regulation of utilities. Meanwhile, in Europe, the mainly publicly owned utilities posed less need for regulation. 
Although the literature points to theoretical and applied issues of the incentive properties of ROR approach to regulation, it is important to recall that ROR once represented an improvement to unhindered public monopolies in terms of price, quality, and output. It is noteworthy that already during the inception years of energy utilities in the 1880s some innovative incentive regulation models were adopted but these were often not continued. Part of the reason for the abandoning the early incentive regulation attempts was the nationalisation of the sector. In the UK, the standardisation of the UK electricity industry became possible with the centralisation of the sector following the establishment of National Grid in 1926 (Jamasb and Pollitt, 2007).

Since Averch-Johnson (1962) showed the inherent weakness in the incentive properties of ROR regulation in the form of a tendency to over-invest, the theory and practice of economic regulation have made some progress. Leibenstein (1965) presented the concept of X-inefficiency which refers to inefficiency due to the absence of competitive (external) or ownership (internal) pressure and asymmetry of information between the principal and the agent. Firms in both competitive or regulated sectors are not immune to $\mathrm{X}$ inefficiency. Akerlof (1970) show that information asymmetry in regulated and competitive industries can lead to the agency problem. In regulated industries, the management can be thought as being an agent with two principals - i.e. the shareholders and the regulator (Jensen and Meckling, 1976).

A practical model for incentivising efficiency in regulated utilities was first presented in Littlechild (1983) as the RPI-X formula with a price or revenue cap. The theoretical notion that the performance of regulated utilities can be improved by mimicking market competition was proposed in yardstick competition in Shleifer (1983). This suggested that the performance of utilities can be assessed relative to some measure of average performance in the sector. Later, Laffont and Tirole (1993) presented the menu of options approach as a means to reducing information asymmetry between the regulator and the firms.

However, given the rapid pace and dynamics of change in the energy sector mainly fuelled by technological progress and policy objectives, both the theory and practice of regulation need to catch up with the requirements of rapid developments in these sectors. Also, translating some theoretical concepts into workable regulatory practice has proven 
difficult. The goal of regulation should be to prepare the networks to play their role in the future energy system. Figure 1 shows the parallels between the technological and regulatory evolution of telecommunications and electricity sectors. Ofgem's initiative to develop output-based incentive regulation can be seen as part of this dynamics.

\begin{tabular}{|c|c|c|c|}
\hline & $\begin{array}{c}\text { Pre-Reform: } \\
\text { Before 1990s } \\
\text { Public Service } \\
\text { ROR } \\
\text { Regulation }\end{array}$ & $\begin{array}{c}\text { Reform: } \\
\text { 1990s-2000s } \\
\text { Commodity } \\
\text { RPI-X } \\
\text { Regulation }\end{array}$ & $\begin{array}{c}\text { Post-Reform: } \\
\text { After 2000s } \\
\text { Service } \\
\text { Output-Based } \\
\text { Regulation }\end{array}$ \\
\hline Telecommunications & Wired Service & $\begin{array}{l}\text { Wireless } \\
\text { Service }\end{array}$ & Data Service \\
\hline Electricity Sector & Deregulation & $\begin{array}{l}\text { Distributed } \\
\text { Generation }\end{array}$ & $\begin{array}{c}\text { Products and } \\
\text { Energy Services }\end{array}$ \\
\hline
\end{tabular}

Figure 1: Evolution of telecommunications and electricity sectors

\section{Source: Jamasb and Llorca (2019)}

The RIIO-1 regulation framework has succeeded in delivering the specified sets of outputs for the regulated energy network companies at the outset of the regulatory period. However, Ofgem's own and their commissioned assessments of RIIO-1 expect higher than anticipated returns among the companies almost across the board (CEPA, 2018). Within this context, Ofgem is examining potential changes to improve the performance of RIIO-2 price control. A key question arising is how to adjust the incentive properties of RIIO in order to deliver a defined set of outputs more efficiently.

The suggested changes to RIIO-2 span over several areas and incentive properties and each can potentially influence the performance and behaviour of the utilities. The pursuit of reducing information asymmetry has made the regulatory framework for the next control period somewhat complex. Thus foreseeing the net effects of the combined changes is difficult. In addition, a complex regulatory system can become less transparent and less accessible to third parties to understand and engage with. Solimene (2011) argues that although the regulatory frameworks in the UK and Italy have gradually become complex, the issue of information asymmetry persists. 


\section{Length of Regulatory Price Control}

As natural monopolies, energy networks are, by definition, capital intensive and have assets with long economic lives often between 2 and 4 decades. It can thus be argued that longer price controls are a better fit for the capital intensive and cyclical nature of investments in energy networks. The length of a price control is a key part of a regulatory contract. In incentive regulation context, it signals a regulatory commitment to a given scheme for the duration of a fixed period.

Most price controls in the utility sector are in the range of 3-5 years. The duration of the price control in RIIO-1 was 8 years which is longer than the norm. Ofgem considers that RIIO-2 should revert back to 5-year price controls. Given the long economic life of many key network assets and investment cycles, an 8-year price control appears to be closer to the optimum length than a 5-year price control. A sub-optimum investment length can, in turn, lead to sub-optimum incentives and investment decisions for the companies.

At the same time, regulators may prefer shorter price controls in order to retain the ability to modify the regulation framework, e.g., due to new information or changing economic circumstances. In incentive regulation, the length of price control protects the firms against the early appropriation of efficiency gains achieved during that price control. It is argued that utilities prefer to invest in assets that generate long term revenues and longer price controls offer some assurance for retaining the gains before they are clawed back in subsequent price controls.

In theory, a competitive bidding process can be devised to discover the optimum length of a regulatory contract. Greve and Pollitt (2017) develop a theoretical model for such an auction system for major infrastructure developments. The same concept can, in principle, be used to discover the optimal length of price controls. The difficulties in applying the approach in real regulatory price controls are, however, not insignificant. In practice, different companies may propose different lengths for regulatory contracts. There are practical reasons for using a similar length of time for all networks in a sector. For example, different companies may bid for different price control lengths. Therefore, the optimum market outcome for the discovery of the optimum length of a regulatory contract can be beyond what is deemed desirable by the regulator. 
The cyclical investments and long asset lives on the one hand and the comparatively shorter price controls on the other inevitably lead to short and medium term imbalances between the costs and revenues of the utilities. These imbalances can run across different price control periods and are thus relevant to both the regulators and financing of the regulated firms. The time required by the regulator to align the utility costs and revenues is referred to as the 'regulatory lag' (Rofoss, 1975). The regulatory lag can lead to upward and downward adjustments to prices.

A challenge for the regulator is to balance the costs and revenues of utilities over time across discrete price control periods. It may be possible to develop an adjustment mechanism for Regulatory Asset Base (RAB) to address this issue. However, achieving this balance is difficult due to the long economic life of the assets in the sector, length of investment cycles, and interdependency of investments across regulatory periods. Also relevant is the timing of investments in the regulatory period, in particular, those in final years of regulatory periods which may not have direct bearing for the regulatory decisions concerning the next price control. Baselining the investments of companies can give some indication of the position of a firm in their long term investment cycles.

\section{Length of Price Control and Cost of Capital}

New price controls provide an opportunity to revisit the regulatory framework, including those concerning the cost of equity and cost of debt, as general economic and sectoral financial conditions can change. Rofoss (1975) describes that low interest rates, and strong economic growth in the 1960s in the US, led to double-digit rates of returns and high price-earning ratios in the utilities sectors - i.e. returns comparable to competitive industries. Longer regulatory periods can include provisions for triggering mid-term reviews to address significant unforeseen changes in economic and commercial conditions.

It is feasible to make provisions for the mid-term reopening of price controls regardless of their length. This can be the case for an individual firm or for the whole sector. In the US, both the regulator and companies can call for reopening of a price control or rate case at the request of one party when important new arguments, information, or circumstances 
justify this, which in some instances can otherwise continue until one of the parties call reopening the rate case. This provision is less suitable for incentive regulation frameworks where a central element of the regulatory contract is to give the companies certainty for the duration of the price control period.

The effect of the length of regulatory intervals on cost of capital is inconclusive and the empirical evidence on this is limited. Longer regulatory periods can better incentivise the companies with potential efficiency improvement to explore this potential as the profits gained can be retained for a longer time thus reducing the cost of capital. On the other hand, companies that find it difficult to exceed the regulator's efficiency expectations will have to wait longer to reset their incentives, thus resulting in higher cost of capital (see Frontier Economics, 2013).

A cost of debt indexation mechanism may be a partial remedy. In the UK, clawing back the excess revenues earned within the same price control without breaching the regulatory contract and commitment is difficult. This would also affect the cost of capital as regulatory uncertainty, in a RAB-based framework, is important in forming the profit expectations of long term investors.

In sum, there is an inherent imbalance in the regulation of natural monopolies that arise from the discrepancy in the investment cycles and long economic lives of assets on the one hand and price controls that are often 4-5 years long. The financing of investments with sub-optimum and short regulatory price controls can have a negative effect on the financing and cost of debt of the regulated firms. ${ }^{1}$ This imbalance also relates to the (previously discussed) issue of matching the costs of and revenues from assets over time and across discrete price control periods.

The length of a regulatory period should also consider the mid- and long term uncertainties associated with investing and operating in the sector. At present, the technological and policy uncertainties in the energy networks are significant and can lead to deferral of investments. On the other hand, shorter price control periods allow the regulator to respond more quickly to the changing circumstances in the sector.

\footnotetext{
${ }^{1}$ In general any price control period shorter than the life assets can be viewed as being suboptimal.
} 


\section{Adjusting the Cost of Equity (CoE)}

Setting a reasonable cost of equity involves examining evidence from a variety of sources and using judgment based on the context, timing, and even objectives. The search for an appropriate cost of equity does not imply that there is an objective or unique correct level of cost of equity that needs to be identified. This is also evidenced in the differences in the allowed cost of equity in different countries and jurisdictions. CEER (2017) reports the methodologies, allowed cost of equity, and cost of equity in different European countries. Similarly, there are significant differences among the Public Utility Commissions (PUCs) in different states of the US. ${ }^{2}$

The proposed reduction in the allowed cost of equity $(\mathrm{CoE})$ for the RIIO-2 model relative to RIIO-1 model can affect the earnings of the companies. The change in the incentive strength of CoE can then change the behaviour of the firms. Revisiting the methodology or the level of allowed $\mathrm{CoE}$ is in the discretion of the regulator and can be triggered by changes in the economy, financial sector, or performance of the companies. A reduction in the CoE in RIIO-2 is not out of step with the recent trend observed in recent years in Europe. CEER (2017) indicates a tendency towards lower CoE in member countries of the European Union. In Norway, for example, changes in the financial markets led to a change of methodology for calculating the CoE (Langset and Syversten, 2015).

In an incentive regulation framework, RPI-X models can offer strong efficiency incentive for the utilities. The X-factor could be set individually based on the firm's own costs or based on some measure of relative efficiency to best practice or performance of the sector. On the other hand, the Weighted Average Cost of Capital (WACC) or a change of it can affect the firms' rate of return. ${ }^{3}$ The WACC can be influenced by RPI-X through the cost of debt and risk premium. A high RPI-X can signal that exceeding the expected efficiency improvements will be harder and increase the risk and reduce the expected profits. Thus, the prospect of tougher efficiency requirements and lower future profits can increase the risk premium.

\footnotetext{
${ }^{2}$ See, e.g., AEE Power Portal database. https://powersuite.aee.net/portal

${ }^{3}$ WACC is the weighted average cost of debt and equity. Some regulators make allowances for the cost of capital using a reference share of equity and debt but allow companies to choose their capital structure.
} 


\subsection{X-factors, WACC, and Investments}

In a study of regulation models and investment in selected European companies, including some UK gas and electric network utilities, Cambini and Rondi (2010) find that companies under incentive regulation tend to invest more than firms that are subject to ROR regulation. They point to Armstrong and Sappington (2006); Guthrie (2006); and Vogelsang (2006) who argue that such an outcome can occur. It is possible that incentive regulation and fixed-period price controls lead to more focus on short-term efficiencyenhancing investments, while ROR regulation encourages long-term (over)investment. Such outcomes may seem to counter the theory and intuition of incentive regulation but are plausible in certain conditions. Cambini and Rondi (2010) also find positive, but insignificant, effect on investments from both WACC and a change of WACC.

Vogelsang (1999) discusses the relationship between the X-factor and utility investments and suggests that $\mathrm{X}$-factors should not exceed the rate of technical improvement. A lower $\mathrm{X}$-factor should result in higher investments. Volgelsang (1999) then suggests a two-part tariff model for a transmission company linking the variable fees to short-term efficient use of capacity while the fixed fees are more closely linked to (long term) investment needs. Cambini and Rondi (2010) find a negative and highly significant effect of X-factor on investments. Incentive regulation and RPI-X can promote cost-saving and, at the same time, encourage (short term) efficiency-enhancing investments. Poudineh and Jamasb (2015) find efficiency-enhancing investment effects of incentive regulation in the Norwegian electricity distribution utilities. The utilities seem to undertake investments that improve their efficiency in a given price control period.

Abrardi et al. (2018) report a similar study as in Cambini and Rondi (2010) with longer data (1997-2013) from a number of European, Latin American, Middle Eastern and North African countries, excluding UK utilities. They find that firms, under incentive regulation, tend to invest more than those under ROR regulation. However, contrary to Cambini and Rondi (2010), they find that investments seem to be more driven by the WACC than by the RPI-X factors.

A comparison of the conclusions of the above two studies suggests that the context and factors such as the maturity of incentive regulation can influence the relative effect of RPI-X vs. WACC on investments. It is normally expected that effective incentive 
regulation would reduce the inefficiency gap among the firms in the sector. ${ }^{4}$ Therefore, over time, the RPI-Xs will be expected to become smaller and be within a narrower range, and thus increase the relative importance of the WACC for investment decisions. In addition, as firms become more accustomed to the incentive regime, uncertainty is reduced and investments can increase. It is, therefore, plausible that the incentive power of a WACC, when sufficiently high, can exceed the efficiency incentives of low RPI-Xs. It should be noted that, while WACC levels are the same for all the firms in the sector, the RPI-X factors are normally firm-specific. As a result, high RORE levels across the board in a sector can indicate that the incentive effect of the WACC has been greater than those of the RPI-X factors. Therefore, the relative strength of WACC vs. RPI-X incentives may be the deciding factor rather than their (absolute) levels.

The similarities and contrasts between a conventional ROR regulation and a revenue cap model in terms of their incentive powers can be illustrated through the simple formula in Equation (1):

$$
R=b \bar{R}+(1-b) C
$$

where $R$ is the allowed revenue, $\bar{R}$ is the norm measure of revenue, $C$ is a utility's total costs, and $b$ denotes the incentive power of the regulation regime. The incentive power $b$ reflects the degree to which the utility's allowed revenues will be based on own (actual) costs versus some estimated norm or benchmarked costs (see Newbery, 1998). When $b=0$, the equation represents a ROR model where the allowed revenue is fully based on the utility's own costs. On the other hand, when $b=1$ the formula represents a strong price control where revenues are fully based on the norm costs determined by the regulator such as through cost efficiency benchmarking.

In Norway, the energy regulator (NVE) has used a value of $60 \%$ for $b$, implying that the allowed revenue of the firms is $60 \%$ based on their norm (efficient) costs based on firmspecific X-factors derived from cost benchmarking, and the remaining $40 \%$ are based on the utilities' own costs (Jamasb and Poudineh, 2015). In Norway, the norm costs are derived from $\mathrm{X}$-factors that are intended to close the efficiency gap between less efficient

\footnotetext{
${ }^{4}$ A narrowing of efficiency gap among the firms would also allow the regulator to use yardstick regulation based on sector average performance.
} 
firms and the frontier (best practice) firms using the Data Envelopment Analysis (DEA) technique.

The higher the incentive power, the more important WACC and X-factor become in determining the firm's profit. However, as indicated earlier, as an incentive regulation regime matures, and efficiency improvements by exceeding the $\mathrm{X}$-factors become more difficult to achieve, the relative importance of WACC as a determinant of investment is likely to increase. Indeed, over time, as the efficiency differences among the firms are reduced, the X-factors can be expected to become more similar and gradually move towards average productivity of the sector.

Cost efficiency and savings beyond that implied by X-factor result in higher than expected return on equity. These cost savings may originate from Opex and Capex. A lower cost of equity also implies a reduction in the allowed revenue $R$. From a company point of view, for a given revenue level, marginal efficiency gain from Opex or Capex should be equal, somewhat similar to the equi-marginal principle of cost-effectiveness. In other words, a reduction in cost of equity $(R)$ could result in lower Capex and Opex such that this equi-marginal equilibrium is maintained.

The marginal costs of attaining certain outputs, and thus the equi-marginal equilibrium, vary across the companies as in the case of marginal cost of quality of service for the UK electricity distribution networks (Jamasb et al., 2012). Everything else being equal, at the margin, a lower cost of equity can change the balance of risk-adjusted marginal efficiency improving expenditures from Capex towards Opex. Given that efficiency gains from Opex tend to be short-term gains, a lower cost of equity can result in lower long-run efficiency efforts and innovations. This assumes a degree of substitution between Capex and Opex. It is noteworthy that in some cases Capex and Opex are complementary.

In addition to financial considerations, choosing a cost of equity is a balancing act. In isolation, a low real cost of equity can result in fewer investments. At the same time, in an incentive regulation framework, a lower COE can focus the investment efforts of utilities to where the efficiency gains are the highest. This effect can be further strengthened where the regulation model also provides Totex incentives. 


\subsection{Cost of Equity (CoE) and Cost of Debt (CoD)}

The cost of debt CoD and allowed return on equity are linked. A higher allowed return on equity improves the terms of obtaining and servicing the debt. A reduction in allowed return on equity has the opposite effect and results in a higher cost of debt. A lower allowed return for equity (and perhaps higher $\mathrm{CoD}$ ) can, in turn, dampen the willingness of capital providers to invest.

It is helpful to distinguish between the method of calculation of the cost of debt by the regulator, the numerical exercise, and the actual cost of debt resulting from these. A change in the calculation method of the allowed cost of equity can potentially be a source of regulatory risk. The change can, however, be justified by changes in economic conditions. On the other hand, changing the values of the components of the allowed $\mathrm{CoE}$ is a different risk. As Prage (1989) argues the cost of capital is not exogenous to the regulatory process. Therefore, these risks can be viewed as being somewhat controllable by the regulator, i.e. the regulator is aware that a change of the method or numerical values can increase the CoE and in turn the CoD.

The debate on allowed $\mathrm{CoE}$ and $\mathrm{CoD}$ is relevant for investments. The challenges for and expectations to energy network utilities in the coming years justify an emphasis on multidimensional objectives and dynamic efficiency as opposed to the relatively static efficiency promoted by the early incentive regulation frameworks using benchmarking and price/revenue caps. The RIIO framework represents an intention to move in this direction by promoting innovation (Jenkins, 2017).

How this dynamic is conceptualised, motivated, and achieved is important for regulation and as a research topic. Achieving dynamic efficiency, in a changing operating environment, through innovation involves some financial risk for the companies. Therefore, a higher allowed $\mathrm{CoE}$, even for specific activities, may promote innovation in the sector (see Appendix). The regulator's challenge is to identify and reward investments which lead to real efficiency gains as opposed to gains arising from high-cost estimates and forecasts in companies' business plans. An effective Totex Incentive Mechanism (TIM) can help reduce the need to adjust the returns ex-post. 


\section{Information Asymmetry and Incentives - Business Plans and Sharing Factors}

In RIIO-1, the Totex Incentive Mechanism (TIM) was based on the analysis of companies' forecasts of their Capex, the regulator's view of efficient costs, and a benefitsharing factor. A component of RIIO-1 is the Information Quality Incentive (IQI) mechanism. The scheme rewards companies whose Capex forecasts are close to those of Ofgem's assessments and thus increase confidence in the forecasts. The mechanism rewards companies with higher incentive rates than those with high Capex forecasts.

The IQI bears an element of the "Menu of Options" theory originally presented in Laffont and Tirole (1993). Menu of options is used as a means to reduce the information asymmetry between the firm and the regulator and allows companies to choose among a set of pre-defined options by the regulator. By choosing among the options the companies reveal information about their efficiency improvement potential.

However, if the information revealing incentive for accurate investment forecasts is not strong, companies can disregard the incentives and report conservative high spending forecasts to maximise profits. Another reason to exaggerate Capex spending is the uncertainty about future policies towards the sector and performance against the targets set by the regulator.

Given the weak response by the companies to the IQI mechanism, Ofgem aims to replace this with a Business Plan Incentive (BPI) mechanism. The BPI is a broader scheme in scope than IQI. Whereas IQI was largely concerned with Capex forecasts, the BPI mechanism requires the companies to present realistic but ambitious business plans that cover both costs and other outputs such as service quality. The quality of the business plans presented can then be rewarded or penalised by up to $+/-2 \%$ of the companies revenue (Ofgem, 2019). The BPI also bears some features of Menu of options as companies need to consider the trade-offs among the alternative output mixes they present in the business plans.

A source of (dis)incentive to exaggerate spending forecasts is the use of sharing factors to allocate the achieved benefits between the company and its customers. The higher the sharing factors, the stronger the incentive is to report higher spending forecasts to ensure 
a high profit. It should be noted that the regulator can disallow forecasts of expenditures that are deemed unreasonable. A low sharing factor, on the other hand, bears some resemblance to pure ROR regulation where the incentive to improve efficiency is weak (Jenkins and Perez-Arriaga, 2017). A combination of low sharing factor and uncertainty about future performance can also lead to high spending forecasts. Therefore, both low and high sharing factors can encourage high Capex forecasts.

In RIIO-1, the company-specific sharing factors are determined by the IQI mechanism. In order to avoid behavioural change from information asymmetry, Ofgem also awards a one-off reward for the accuracy of cost forecasts as well as a sharing rate, from a menu of options (Ofgem, 2018). The one-off incentive is to encourage the firms to provide accurate Totex forecasts. Ofgem's assessments indicate that companies have not fully exploited the potential rewards built into the IQI and the menu of options. It appears that the scheme has helped the firms to avoid net penalties ${ }^{5}$ but it has been less effective in reducing information asymmetry as intended by the regulator. ${ }^{6}$

Ofgem could publish the menu of options and the associated incentive rates, although this could also lead to a change of behaviour by the companies. Alternatively, one may consider an approach where the company can propose own menu of options to stakeholders among which the firm is indifferent in terms of cost. Stakeholders can then choose among options that have different values to them but have the same cost. This approach is outlined in Tobiasson and Jamasb (2016) in the context of socially sensitive network development projects. Menu of options has some appealing theoretical properties. However, as the discussion and evidence above indicate implementing such schemes is not simple.

Analysis by Ofgem suggests that the Totex incentives have not been as effective as intended. Here it may be useful to distinguish between the methods of one-off incentives and sharing factors with the strength of the rates used. A question that arises is the extent

\footnotetext{
${ }^{5}$ The net impact of the upfront reward/penalty and sharing rate are taken into account).

${ }^{6}$ This may be because firms are aware that they are able to influence the view of the regulator on the level of efficient cost, resulting in relatively weak upfront penalties that are more than outweighed by rewards from in period outperformance.
} 
to which a revenue cap regulation can be effective with the incentives stemming from own cost forecasts of firms than other approaches such as cost benchmarking.

Two approaches can be considered. First, one could rely on ex-ante incentives and Xfactors derived from each firm's past performance. This requires addressing possible forecasting and benchmarking errors especially when networks are expected to undergo a transition to new technologies (e.g., distributed generation, demand response, or storage) and regulatory requirements (Jenkins and Perez-Arriaga, 2017). There are examples of this in the US where many Public Utilities Commissions (PUCs) have few utilities to regulate and cost benchmarking is not common. Second, one could consider, ex-ante incentive mechanisms based on efficiency benchmarking as practised in revenue and price cap models. If implemented carefully, the above approaches can be, at least, as effective as the current scheme with regards to information asymmetry.

Ofgem also considers using a Blended Sharing Factor $(\mathrm{BSF})^{7}$ mechanism for setting the level of the sharing factors. The aim is to improve the assessment of the costs for the delivery of the companies' business plans. The BSF distinguishes between highconfidence baseline costs and low-confidence baseline costs. Costs assessed as having high-confidence are those that Ofgem can reaffirm using own assessments and data and independent of the companies' own forecasts. These cost types can be assigned higher sharing factors. Conversely, a low sharing factor will be given to costs in which the confidence level is low. The sharing factors to be used are in the range of $15 \%$ to $50 \%$ from the lowest to highest confidence levels (Ofgem, 2019). The high end of the sharing factors is similar to those used in RIIO-1. The final sharing factor given to each company is a single weighted average of the different blended sharing factors. One aim of the BSF mechanism is to limit the scope for windfall profits arising from hard-to-assess costs, but firm-specific blending sharing factors have also potential weaknesses.

- First, the cost categories, e.g. low-confidence or otherwise, to which the different sharing factors are applied can be linked. In other words, the sharing factors need to consider inseparability and interdependence of the cost categories.

\footnotetext{
${ }^{7}$ Subsequently renamed as a 'Confidence Dependent Incenticve Rate'.
} 
- Second, the blended sharing factors need to be set independent of the information provided by the companies. This is in order to reduce the effect of information asymmetry. This, however, involves a degree of subjective judgement.

- Third, relates to whether blended sharing factors and overall sharing factors are strong enough to incentivise the companies to reveal some of their information advantages. If the incentives are not strong, companies may not respond to them. A related issue is whether the reduction in information asymmetry is worth the cost of incentives offered to acquire it.

- Fourth, the information required for setting firm-specific sharing factors is not insignificant. Moreover, assigning individual sharing factors to each company based on the information available for them inevitably involves a degree of differentiated treatment of firms. Using similar sharing factors for similar classes of costs can be considered to offer a level playing field.

\section{Menu of Options - A Value-Based Approach}

RIIO uses stakeholder engagement with the utilities in specifying the bundles of outputs and their delivery. It is often observed that regulators have difficulty reducing the information asymmetry between the agency and the firms. This information asymmetry is, by extension, likely to be larger in the case of stakeholders which tend to be less specialist and resourceful than the regulator to engage effectively with the companies. If stakeholder engagement is to maintain a significant role in RIIO-2, it may be possible to further explore ways that this approach can be strengthened. One potentially useful approach is to explore the use of a modified form of menu of options.

We can utilise the concept of menu of options in a customer value-based approach. In this approach, the utilities can propose a set of alternatives in a menu of options as bundles of outputs which can be similar in cost. The customers may, however, not be indifferent among the different bundles of outputs in the menu and place a higher value on some of the options than on others and choose the most desired value option.

This approach can lead to higher customer utility at a given cost level to the utility. This method thus represents a Pareto-improvement and welfare enhancing effect for the 
customers. It is noteworthy that such an application of menu of options does not necessarily exclude the use of conventional menus of options elsewhere in the incentive regulation framework.

\section{Return on Regulated Equity (RORE) and Profit Sharing}

Profit sharing can be conceptualized as being on a spectrum between the pure form of ROR regulation and price regulation regimes. The former remunerates cost of service with a pre-determined return on the regulatory asset base while the latter decouples the price from own cost of the firm. A price regulation that aims to achieve a specific rate of return can resemble a ROR regulation. Profit sharing can be used with ROR regulation to provide an incentive for efficiency improvement.

In price regulation, efficiency incentives already exist and profit sharing aims to limit excess earnings by the companies (Mayer and Vickers, 1996). Price regulation normally results in a higher cost of capital than ROR regulation (Alexander and Irwin, 1996). Profit sharing and regular price controls can reduce the cost of capital. The former effect can be due to reduced risk of regulatory taking and the latter can vary during a price control period (Gandolfi et al., 1996). The incentive for efficiency and innovation can, however, be lower as a result.

Under RIIO-1 price control, most companies seem to be set to earn higher than expected profits due to: (i) real efficiency gains, (ii) high expenditure forecasts in Totex forecasts, or (iii) windfall gains from events such as milder winters with fewer incidents. While the former source of efficiency is desirable, the latter stems from inaccurate budgets and high spending forecasts. Ofgem believes that high-cost forecasts account for a share of the excess earnings by companies. The possibility for reporting high spending forecasts is facilitated by the ex-ante incentives to outperform results that are largely based on own forecasts. Regulators can claw back real efficiency gains by internalising them in subsequent price controls. However, virtual efficiency gains based on exceeding own forecasts bear no real benefits for customers and can lead to a repeated game of exceeding performances set from constantly moving baselines in subsequent price controls. 
Can adjusting or capping the RORE be effective in preventing excess profits? Ofgem has indicated that alternative approaches can be used to limit windfall profits and strategic response from firms. A Return Adjustment Mechanisms (RAM) is considered for return levels above a pre-determined cap or below a floor. RORE outside of this range can trigger the RAM which is also a form of profit sharing mechanism. While RAM can limit the excess profits of companies it is not an efficiency improvement mechanism. Rather, it is a return on equity control of last resort. The design and the return band triggering the RAM is key in determining the effects of the mechanism. As an incentive mechanism, and in isolation from other mechanisms, a RAM with a narrow band, can reduce investment and innovation and increase the risk premium of companies. However, a wide return band can ensure that the mechanism protects the companies and their customers from unforeseen circumstances and performance levels.

At the same time, the RIIO framework uses a Totex Incentive Mechanism (TIM) an element of which is a sharing factor. ${ }^{8}$ As part of the BSF mechanism (discussed above), Ofgem is considering to lower the strength of the incentive with a sharing factor that ranges from $15 \%$ to $50 \%$ and reflect the degree of confidence in rigour of the submitted business plans to reduce the incentive to inflate cost forecasts. An effective TIM should reduce the need for RAM.

A price cap with frequent price controls is effectively an implicit form of profit sharing that allows the regulator to claw back the gains achieved in one period in subsequent price controls. Therefore, an additional layer of profit sharing, combined with shorter price control periods, can have an incentive-reducing effect on the efficiency improving motivation of the firms. In addition, a reduction in the incentive rate (sharing factor) can further reduce the motivation for efficiency improvement. It is noteworthy that benefit and loss sharing mechanisms are normally not symmetric given that utilities are normally protected against the risk of incurring losses over long periods and bankruptcy. At the same time, the regulator aims to prevent the firms from gaining too high returns.

A generous profit sharing mechanism can encourage efficiency improvement but it also implies that the efficiency potential can be underestimated. Greenstein et al. (1995) analyse the investment rates of US telephone exchange companies and find price

\footnotetext{
${ }^{8}$ The sharing factor can result in both instant gains or returns that can be realised over several years.
} 
regulation more effective than profit sharing. The study also found that price regulation is less effective in infrastructure development when combined with profit sharing.

A reduction of RORE does not address the underlying cause of excess profits of the firms. A profit-sharing scheme for Totex can be more effective in achieving this objective than a capped RORE. A combination of shorter price control periods and lower sharing factors will likely lower the incentive to invest compared to longer price controls with higher sharing factor, although due to information asymmetry, more of the efficiency gains in the latter case could be accrued to the firms. The regulator can incentivise innovation and efficiency through separate targeted measures although the drivers of efficiency of the companies may become less tractable in the process.

Profit sharing can take explicit and implicit forms. They can be part of a TIM, part of a targeted incentive, or the RAM. Implicit sharing can be in the form of shorter price cap periods to capture the benefits of efficiency gains. Profit sharing schemes can differ in terms of the purpose they serve: (i) providing an incentive for innovation and efficiency with lasting effect, or (ii) controlling the returns and sharing them with customers.

- A profit sharing mechanism linked to a TIM can lead to efficiency improvement in Totex with lasting efficiency gain that can be retained for future price controls.

- A profit sharing mechanism through targeted incentives are not economically efficient (Section 7), but also less necessary as the regulation matures over time and imbalances in delivery of different outputs are reduced.

- A return adjustment mechanism such as RAM, from an economic point of view, protects consumers in the short-run. However, it does not reduce information asymmetry and lead to foregone efficiency and innovation in the long run.

\section{Targeted Output Incentive Schemes}

The RIIO-1 included a set of targeted incentives designed to improve output delivery and performance in specific priority areas. Given that companies respond to suitably strong incentives, a question that arises is whether an incentive scheme comprising a set of targeted incentives is economically efficient or it can prevent achieving overall cost efficiency potential of the firms. 
In the early price controls, there are often certain priority areas where it is important to improve performance such as quality of service, network energy losses, and customer service. Some regulators may keep such priority areas outside of the cost benchmarking and subject them to targeted incentives. Over time, as performance in these areas improves, regulation can move from targeted incentives to global incentive schemes. For example, the social cost of service interruption and network energy losses can be incorporated in an overall cost benchmarking model (Jamasb and Nepal, 2016). The utilities can then freely trade-off the cost of different outputs in order to minimize their overall costs.

From an economic viewpoint, a single global incentive scheme such as Totex based cost benchmarking is more efficient than using several targeted schemes. Targeted incentive schemes can prevent the companies from equating their marginal cost of efficiency improvement to marginal benefits of the improvement. Instead, the companies will pursue several marginal cost and benefit equilibria within the targeted incentivised areas to maximise profits. The overall outcome of several partial cost minimisations would be less efficient than achieving a global cost minimisation. This can occur even when companies exceed their expected performance in individual targeted areas.

Some practical issues and considerations make the use of single global incentives difficult. However, as each targeted incentive schemes result in some inefficiency in terms of limiting the trade-offs available to the companies, their use can be justified by wider (social) benefits. This is not to say that targeted incentives should not be used. Regulators have social, environmental, technical, and other objectives and preferences which require deviating from economic efficiency. However, as a general rule, targeted incentive schemes need to be used sparingly in performance areas that are of key strategic importance.

Another question that arises is the degree to which different targeted performance areas and their incentive schemes are separable. For example, a given amount of Opex and Capex spent (or saved) may affect both quality of service and network energy losses. Companies may be able to use the synergies across these areas to benefit from more than one incentive scheme for a single effort. 


\section{Quality of Service}

A reduction in RORE would generally be expected to result in lower investments. This may, however, come at the expense of investments in areas of significant importance such as in the quality of service (QoS). The regulator can then choose to incentivise QoS within a cost benchmarking or through targeted incentive penalty and reward schemes. An advantage of the former approach is that the firm can trade-off one output against another outputs, while the latter is more direct and effective in terms of achieving specific objectives.

The Norwegian regulator follows the former approach and includes the socio-economic costs of service interruptions and the system cost of network energy losses in the Totex of the companies. The regulator has recently, recognising the increasing value of the electricity services to consumers, introduced an increase in the cost of quality of service of about $50 \%$.

In general, Opex is more relevant for short-term and operational measures, while Capex is concerned with long term measures such as replacing assets or modernisation of the network. This is broadly the case for QoS. The marginal cost of QoS is different across the UK utilities. At the same time, QoS can be improved through Opex (restoration of service and maintenance) or Capex (e.g. for preventive measures) (Jamasb et al., 2012). A lower cost of equity, at the margin, can lead the utilities to achieve short-term improvements in QoS while avoiding the low-return Capex that yields better QoS but it does so in the long-run. A potential risk is that some investment decisions can be put on hold for a period and thus the investment needs accumulate over time.

As pointed earlier, network investments are generally bulky and cyclical and it is important to spread the costs over longer periods where this is possible. Therefore, the risk to consumers, from postponing regular investments, is that short term cost reductions will be followed by cost increases in later periods. A baselining of Totex or major categories of investments can be used to identify deviations from the past. For example, reductions in Totex that may be motivated by changes in firm behaviour and timing of the investment cycles. 


\section{Summary Assessment and Conclusions}

RIIO-1 has been the longest network price control (8 years) in the UK. The model also presents an innovation in utility regulation by attempting to reflect the changing nature of the role and services of the utilities. There are, however, indications that under RIIO-1 most companies have earned high ROREs. This has motivated the regulator to revisit and improve the framework for RIIO-2. In this context, a set of changes are being considered. The combined effect of the proposed changes in the regulation model is however difficult to determine and will also depend on the details of implementation.

The main sources of the excess RORE in RIIO-1 are (i) significant Totex underspend, (ii) over-performance in some targeted incentivised areas, and (iii) real price effects during the regulatory period. Removal of the IQI scheme might alleviate the former issue, or measures such as the RAM can, although presenting own disincentives as discussed, also be considered. The latter needs to consider the possible overlaps between different incentive areas and their relation to Totex. It is likely that some targeted performance areas have been effective in improving performance across the sector. These performance areas can be considered for inclusion in efficiency benchmarking of utilities. This will, in principle, allow the companies to trade-off delivery of different outputs more efficiently and move closer to a global cost minimisation than in isolated performance areas.

The change in the cost of equity is a significant step. However, how this change interacts with other elements of price controls and incentive is less clear. Adjusting the cost of equity is justifiable when there are significant changes in the underlying risks or returns to equity capital, though not as an instrument of incentive regulation.

Ofgem has made efforts to reduce the information gap in relation to the companies by incentivising and requiring considerable amounts of information from them. A theoretical advantage of incentive regulation with benchmarking is that it can rely on relatively small amounts of data and use comparisons. The information asymmetry problem is inherently difficult to gauge and overcome by acquiring more information from the firms. In a sense, this asymmetry cannot be objectively determined by the regulator. Rather, this asymmetry is a latent form of knowledge the extent of which may only be discovered, even by the firms themselves, through incentives and the regulatory framework. 
The role of cost-saving for efficient and affordable delivery of energy services is evident. However, an important function of the energy networks is to support the delivery of a future low-carbon energy system. Therefore, the overall system benefits of investments and spending should be viewed within the wider context of the system benefits they create and support than a network service in a narrow sense.

Regulators can use analytical tools to reduce information asymmetry and as a platform for discussions with companies. Kuosmanen and Nguyen (2018) suggest model simulations for analysing the effects of regulation models. Also, norm models can be a useful tool for assessing investment options and have been used in Spain, Peru, Chile, and Sweden to reduce information asymmetry where the information from companies was not available or reliable. Norm models are engineering models of actual or ideal networks using the GIS coordinates of the demand nodes and estimated capital and operating costs (Jenkins and Perez-Arriaga, 2017). Norm models, however, lack some properties of an effective incentive regulation tool. Jamasb and Pollitt (2008) compare the incentive and economic properties of norm models with benchmarking based models in Sweden.

Incentive regulation of distribution networks in the UK and the RIIO framework have over time evolved from a group-based benchmarking background towards a more firmlevel regulation. This may have been due to the lack of sufficient progress in improving the performance among the utilities in the initial price controls. RIIO, as an output-based framework, has a sharper focus on the transition of networks to support a low-carbon energy sector. Therefore, there is a need to design incentives that promote innovation for dynamic and long-term efficiency.

RIIO is an output-oriented approach. In this approach, information asymmetry is more critical than in the more common "input-oriented" models. Consequently, this has influenced the design of RIIO. A question is whether, at the presence of information asymmetry, simpler or more detailed incentives are better suited for the purpose. The IQI scheme with ex-ante incentives did not tackle the difficult information asymmetry problem but might have become a source of excess RORE through inflated cost forecasts. As noted, the IQI scheme is to be replaced with a Business Plan Incentive (BPI) scheme. This is likely to reduce the profits gained from Totex reduction and excess RORE. 
Given the difficulty of devising effective incentive mechanisms to promote efficiency and innovation and combining this with shorter price controls and less profit from Totex, the performance drive of companies may become more short-termist. Thus, the proposed changes to RIIO may, on balance, cause a shift towards Opex saving as a source of profit. While RIIO does not distinguish between Opex and Capex, this can influence short term vs. long term efficiency-enhancing efforts of companies.

The key issue is the cumulative effect of the adjustments under consideration. This summary aims to inch closer towards an answer.

- Information Quality Incentives (IQI) and menu of options - RIIO-1 has relied on the IQI scheme using the information and forecasts from the companies to design the menus. This appears to have been a source of the expected high returns by the companies. The information requirement for menu design can originate from (i) companies own forecasts, (ii) companies past performance (baselining), or (iii) independently determined by the regulator (e.g., from norm models). The gains to the regulator from the reduction of information asymmetry might be surpassed by gains from reported cost forecasts by the companies. Less reliance on IQI or the companies as the main source of information for menu design and upfront rewards can reduce the cost of information asymmetry. One option is to rely less on information supplied by the companies. Instead, incentive schemes based on business plans and benefit sharing factors that rely more on historical information and confidence in own assessments can be used.

- The Totex Incentive Mechanism (TIM) and Blended Sharing Factors (BSF) are key components of RIIO. A reduction in sharing factors for Totex is being considered. The sharing factors would be determined through the BSF approach that reflect the degree of confidence in the underlying information. The lower the sharing factors the more the incentives resemble those of a ROR regulation by making the firms less motivated to improve efficiency. A lowering of sharing factors also implies that significant information asymmetry remains. Thus, if the information advantage of companies is reduced, for example, by relying less on the companies for cost forecasts, there will be less need for lowering the sharing 
factors. The objective is to promote lasting efficiency gains and avoid 'virtual' efficiency gains from inaccuracy in expenditure forecasts.

- Output Delivery Incentives (ODI). As discussed, targeted incentives in selected outputs and performance areas are not economically efficient as they divide the companies efforts into different activity areas that are incentivised separately. The outcome would likely be less efficient than when companies attempt to achieve global efficiency. The use of targeted incentives should, therefore, be limited to areas where performance improvement is crucial and other benefits of the incentive mechanism justify the potential efficiency loss from this.

- Return Adjustment Mechanism (RAM). The discussion of the RAM suggested that it is mainly an instrument of last resort. When other incentive mechanisms are effective and well-calibrated the need for the RAM should be significantly reduced.

In sum, at the time of RIIO-1, the model was developed based on the idea that the utilities sector is on the verge of major changes. Hence there was a need for a new approach to the regulation of energy networks. The need for a regulatory model that is fit for future challenges of the sector is even stronger in the present time. This paper discusses aspects of how a revised RIIO model can pursue this objective. It is not a definitive assessment of the cumulative effect of incentive mechanisms of RIIO-2, as these are not unrelated together. However, a few overarching conclusions were drawn.

The desire for reducing information asymmetry and achieving multiple objectives should not result in complex incentive models. A test of the need for more simplicity is when tracing the effect of a change in the incentive mechanisms proves to be difficult. The number of targeted incentive schemes should, where possible, be reduced to a minimum to promote overall economic efficiency of the utilities.

The utilities sector is capital intensive and is likely to become even more so in the coming years. The role of Capex in long term efficiency improvement and promoting innovation should have a prominent place in an incentive regulation model. The network sector has been difficult to incentivise to adopt new technologies, innovate and experiment. This suggests that parts of the solution to more innovation in the sector mat lie beyond the reach of the regulator alone and needs to be part of an economy-wide effort. 


\section{References}

Abrardi, L., Cambini, C., and Rondi, L. (2018). The Impact of Regulation on Utilities' Investments: A Survey and New Evidence from the Energy Industry. De Economist, 166(1), March, 41-62.

Alexander, I. and Irwin, T. (1996). Price Caps, Rate-of-Return Regulation, and the Cost of Capital, Viewpoint, Note No. 87, September, The World Bank Group.

Armstrong, M. and Sappington, D. (2006). Regulation, Competition and Liberalization. Journal of Economic Literature, XLIV, 325-366.

Averch, H. and Johnson, L.L. (1962). Behavior of the Firm Under Regulatory Constraint. American Economic Review, 52, 1052-1069.

Akerlof, G.A. (1970). The Market for Lemons: Quality Uncertainty and the Market Mechanism. Quarterly Journal of Economics, 84(3), 488-500.

Cambini, C. and Rondi, L. (2010). Incentive Regulation and Investment: Evidence from European Energy Utilities, Journal of Regulatory Economics, 38, 1-26.

CEER (2017). CEER Report on Investment Conditions in European Countries, Council of European Energy Regulators, Ref: C16-IRB-29-03 24, January.

CEPA (2018). Review of the RIIO Framework and RIIO-1 Performance, Final Report, Prepared for the Office of Gas and Electricity Markets (FGEM), March, Cambridge Economic Policy Associates.

Frontier Economics (2013). A report prepared for the Australian Energy Regulator (AER).

Glachant, J.M. (2012). Regulating Networks in the New Economy, Review of Economics and Institutions, 3(1), Winter, 1-10.

Greenstein, S., McMaster, S., and Spiller, P. (1995). The Effect of Incentive Regulation on Infrastructure Modernization: Local Exchange Companies' Deployment of Digital Technology, Journal of Economics and Management Strategy, 4, 187-236.

Greve, T. and Pollitt, M. (2017). Determining the Optimal Length of Regulatory Guarantee: A Length of Contract Auction, The Economic Journal, 127, F325-F333 (October).

Guthrie, G. (2006). Regulating Infrastructure: The Impact on Risk and Investment. Journal of Economic Literature, 44(4), 925-972. 
Hammond, C. J., Jones, G., and Robinson, T. (2002). Technical Efficiency under Alternative Regulatory Regimes: Evidence from the Inter-war British Gas Industry, Journal of Regulatory Economics, 22(3), 251-270.

Jamasb, T. and Llorca, M. (2019). Energy Systems Integration: Economics and Regulation of a New Paradigm, Cambridge Working Papers in Economics CWPE 1903 / Electricity Policy Research Group, Working Paper EPRG 1903, January, Faculty of Economics, University of Cambridge.

Jamasb, T. and Nepal, R. (2016). Delivering Energy Networks Security: Economics, Regulation and Policy. In Delivering Energy Law and Policy in the EU and the US: A Reader. Heffron, R.J. and Little, G.F.M (eds.), Edinburgh: Edinburgh University Press.

Jamasb, T. and Nepal, R. (2015). Issues and Options in the Economic Regulation of European Network Security. Competition and Regulation in Network Industries $16(1), 2-22$.

Jamasb, T. and Pollitt, M.G. (2015). Why and How to Subsidise Energy R+D: Lessons from the Collapse and Recovery of Electricity Innovation in the UK. Energy Policy, 83, 197-205.

Jamasb, T. and Pollitt, M. (2007). Incentive Regulation of Electricity Distribution Networks: Lessons of Experience from Britain, Energy Policy 35(12), 6163-6187.

Jamasb, T. and Pollitt, M.G. (2011). Electricity Sector Liberalisation and Innovation: An Analysis of the UK Patenting Activities, Research Policy, 40(2), March, 309-324.

Jamasb, T. and Pollitt, M. (2008). Reference Models and Incentive Regulation of Electricity Distribution Networks: An Evaluation of Sweden's Network Performance Assessment Model (NPAM), Energy Policy, 36, May, 1788-1801.

Jamasb, T. and Pollitt, M. (2008). Liberalisation and R\&D in Network Industries: The Case of the Electricity Industry, Research Policy, 37 (6-7), 995-1008.

Jamasb, T., Orea, L. and Pollitt, M.G. (2012). Estimating Marginal Cost of Quality Improvements: The Case of the UK Electricity Distribution Companies. Energy Economics, 34(5), 1498-1506.

Jenkins, J.D. and Perez-Arriaga, I.J. (2017). Improved Regulatory Approaches for the Remuneration of Electricity Distribution Utilities with High Penetration of Distributed Energy Resources, Energy Journal, 38(3), 63-91. 
Jenkins, C. (2011). RIIO Economics: Examining the Economics Underlying Ofgem's New Regulatory Framework, Florence School of Regulation, Working Paper, June 2011.

Jensen, M.C. and Meckling, W.H. (1976). Theory of the Firm: Managerial Behavior, Agency Costs and Ownership Structure. Journal of Financial Economics (October), 3(4), 305-360.

Kuosmanen, T. and Nguyen, T. (2018). How Harmful is the Rate of Return Regulation? Averch-Johnson critique revisited.

Laffont, J-J. (1994). The New Economics of Regulation Ten Years After. Econometrica, 62(3), 507-38.

Laffont, J.-J. and Tirole, J. (1993). A Theory of Incentives in Procurement and Regulation, Cambridge: MIT Press.

Langset, T. and Syversten, S.C. (2015). A New WACC Model in the Regulation of the Norwegian Electricity Network Operators, The ICER Cornicle, Edition 4, November.

Leibenstein, H. (1966). Allocative Efficiency vs. X-Efficiency, American Economic Review, 56(3), 392-415.

Littlechild, S.C. (1983). Regulation of British Telecommunications' Profitability, London: HMSO.

Matthews, D. (1988). Profit Sharing in the Gas Industry 1889-1949, Business History, 30, 306-328.

Mayer, C. and Vickers, J. (1996). Profit-Sharing Regulation: An Economic Appraisal, Fiscal Studies, 17(2), 83-101.

Nepal, R. and Jamasb, T. (2015). Incentive Regulation and Utility Benchmarking for Electricity Network Security. Economic Analysis and Policy 48, 117-127.

Newbery, D.M. (1998) 'Rate-of-Return Regulation Versus Price Regulation for Public Utilities', in The New Palgrave Dictionary of Economics and the Law, London: MacMillan.

Ofgem (2019). RIIO-2 Sector Specific Methodology - Core document, Office of Gas and Electricity Markets, 24 May 2019, London.

Ofgem (2018). Totex Mechanism: Analysis of Options, prepared for the academic panel, 17 September, Office of Gas and Electricity Markets, London. 
Ofgem (2010). RIIO - A New Way to Regulate Energy Networks, Factsheet 93, October, Office of Gas and Electricity Markets, London.

Poudineh, R., Tobiasson, W., and Jamasb, T. (2016). Electricity Distribution Utilities and the Future: More than Wires, in Finger, M. and Jaag, C., Eds., Routledge Companion to Network Industries, 297-311, Routledge.

Poudineh, R. and Jamasb, T. (2015). A New Perspective: Investment and Efficiency under Incentive Regulation, The Energy Journal, 37(1), 241-263.

Prager, R.A. (1989). The Effects of Regulatory Policies on the Cost of Debt for Electric Utilities: An Empirical Investigation, The Journal of Business, 62(1), 33-53.

Rosoff, P. (1975). Regulatory Lag and Financing, Proceedings of the Annual Conference on Taxation Held under the Auspices of the National Tax Association-Tax Institute of America, 68, 239-245.

Shleifer, A. (1985). A Theory of Yardstick Competition. Rand Journal of Economics 16(3), 319-327.

Solimene, L. (2011). Increasing Complexity in Electricity Regulation: To whose Benefit?, European Review of Industrial Economics and Policy, No. 2, Selected Papers.

Tobiasson, W. and Jamasb, T. (2016). The Solution that Might Have Been: Resolving Social Conflict in Deliberations about Future Electricity Grid Development, Energy Research and Social Science, 17, July, 94-101.

Vogelsang, I. (1999). Optimal Price Regulation for Natural and Legal Monopolies, Economía Mexicana NUEVA ÉPOCA, VIII, 1, 5-43.

Vogelsang, I. (2006). Electricity Transmission Pricing and Performance-Based Regulation, The Energy Journal, 27, 97-126. 


\section{Appendix 1: Main differences from RIIO-1 and the planned RIIO-2}

\begin{tabular}{|c|c|c|c|}
\hline $\begin{array}{l}\text { Incentive } \\
\text { mechanism }\end{array}$ & RIIO-1 & RIIO-2 & $\begin{array}{c}\text { Rationale for } \\
\text { change/Possible impact }\end{array}$ \\
\hline $\begin{array}{l}\text { Length of price } \\
\text { control }\end{array}$ & 8 years & 5 years & $\begin{array}{l}\text { Rationale: Reduces risk of setting too } \\
\text { high/low allowances ex-ante due to } \\
\text { asymmetry of information. } \\
\text { Possible impact: Might impact } \\
\text { expenditure on innovation as shorter time } \\
\text { period to recover cost of any investment. }\end{array}$ \\
\hline \multirow[b]{2}{*}{$\begin{array}{l}\text { Totex incentive } \\
\text { mechanisms }\end{array}$} & $\begin{array}{l}\text { Information Quality Incentive } \\
\text { (IQI) - consisting of an upfront } \\
\text { penalty/reward. }\end{array}$ & None. & $\begin{array}{l}\text { Rationale: incentive did not operate as } \\
\text { intended possibly due to assumptions on } \\
\text { which it is based not holding in reality. }\end{array}$ \\
\hline & $\begin{array}{l}\text { Sharing factors (ranged from } 47- \\
70 \% \text { ) - each company received a } \\
\text { different sharing factor } \\
\text { determined by the IQI. }\end{array}$ & $\begin{array}{l}\text { Blended sharing factor }(15-50 \%) \\
\text { derived as average of sharing factors } \\
\text { assigned to different cost categories } \\
\text { based on historical cost information. }\end{array}$ & $\begin{array}{l}\text { Rationale: from initial analysis it does not } \\
\text { appear to be a relationship between } \\
\text { sharing factors and how much companies } \\
\text { underspent the totex allowances in RIIO- } \\
\text { 1. It is therefore harder to justify a higher } \\
\text { sharing factor. }\end{array}$ \\
\hline $\begin{array}{l}\text { Incentive on } \\
\text { business plans }\end{array}$ & $\begin{array}{l}\text { Fast-tracking - early settlement } \\
\text { of the price control. Companies } \\
\text { received the highest sharing } \\
\text { factor available (without going } \\
\text { through the IQI process). An } \\
\text { additional upfront reward } \\
\text { equivalent of } 2.5 \% \text { of totex. }\end{array}$ & $\begin{array}{l}\text { Business plan Incentive- upfront } \\
\text { reward/penalty equivalent to a } \\
\text { maximum of }+/-2 \% \text { of totex with } \\
\text { competed pot of money. }\end{array}$ & $\begin{array}{l}\text { Rationale: provide companies with an } \\
\text { additional incentive to reward effort for } \\
\text { ambitious service quality and cost targets. } \\
\text { Also intended as reward for specific } \\
\text { information that might be revealed and } \\
\text { used for other companies in the same } \\
\text { sector (e.g., better understanding of risks, } \\
\text { uncertainty, particularly those that do not } \\
\text { go in favour of regulated companies). }\end{array}$ \\
\hline
\end{tabular}




\begin{tabular}{|c|c|c|c|}
\hline & & & $\begin{array}{l}\text { Possible impact: from feedback received } \\
\text { from companies, proposed size of reward } \\
\text { might not be enough to incentive } \\
\text { participation and effort. }\end{array}$ \\
\hline $\begin{array}{l}\text { Output delivery } \\
\text { incentives }\end{array}$ & $\begin{array}{l}\text { Targets and incentives for } \\
\text { different output set ex-ante for } \\
\text { the entire RIIO period. }\end{array}$ & $\begin{array}{l}\text { Dynamic approach to setting targets } \\
\text { and incentives, which might change } \\
\text { throughout the RIIO-2 period } \\
\text { depending on relative performance. }\end{array}$ & $\begin{array}{l}\text { Rationale: Targets were achieved early in } \\
\text { RIIO-1. Proposal for RIIO- } 2 \text { removes } \\
\text { risks associated with setting outputs at a } \\
\text { low level by maintaining flexibility to } \\
\text { increase targets for these outputs over } \\
\text { time. }\end{array}$ \\
\hline Innovation & $\begin{array}{l}\text { Innovation stimulus provided as } \\
\text { part of the price control through } 3 \\
\text { mechanisms: } \\
\text { a. Annual Innovation } \\
\text { Competition- worth } \approx £ 500 \mathrm{~m} \\
\text { over RIIO-1. } \\
\text { b. Network Innovation Allowance } \\
\text { awarded to each company ( } 0.5 \text { - } \\
0.7 \% \text { of each company's } \\
\text { allowed revenues } \approx £ 500 \mathrm{~m} \text { over } \\
\text { RIIO-1). } \\
\text { c. Innovation Roll-out mechanism } \\
\text {-funding to enable transition of } \\
\text { innovation into business as } \\
\text { usual. }\end{array}$ & $\begin{array}{l}\text { Reform the Network Innovation } \\
\text { Allowance (NIA): } \\
\text { Focusing mainly on projects related } \\
\text { to longer-term energy system } \\
\text { transition and addressing consumer } \\
\text { vulnerability. } \\
\text { Improving public reporting of } \\
\text { projects funded, including costs and } \\
\text { benefits, and demonstrating that } \\
\text { successful innovation is diffused } \\
\text { across the sector. } \\
\text { Instead of automatic allowances } \\
\text { linked to revenue, innovation } \\
\text { allowances would be set based on } \\
\text { justification set out in company } \\
\text { Business Plan submissions. } \\
\text { Replace (a) with a new pot focussed } \\
\text { on major strategic innovation } \\
\text { challenges and open to third parties. }\end{array}$ & $\begin{array}{l}\text { Rationale: Evidence that (b) has been used } \\
\text { to finance O\&M works which should have } \\
\text { been funded through the totex allowance. } \\
\text { Funding for major strategic challenges. } \\
\text { Ensure additionality of new projects. } \\
\text { Possible impact: More operational and } \\
\text { maintenance works funded by totex for } \\
\text { innovations close to transition into BAU. } \\
\text { Might reduce scope for innovation at early } \\
\text { stage of development. Complexity of } \\
\text { governance of new form of (a) might } \\
\text { reduce scope for innovation at early stage. } \\
\text { Difficult to track benefits achieved from } \\
\text { these type of projects. }\end{array}$ \\
\hline
\end{tabular}




\begin{tabular}{|c|l|l|l|}
\hline $\begin{array}{c}\text { Allowance for cost } \\
\text { of equity }\end{array}$ & $\begin{array}{l}\text { 6-7\% (RPI real terms, 7-8\% } \\
\text { CPIH real equivalent). }\end{array}$ & $4-5.6 \%$ (CPIH real terms). & $\begin{array}{l}\text { Rationale: Align allowed cost of equity } \\
\text { with risk faced by regulated network } \\
\text { companies and to account for expectations } \\
\text { of outperformance due to asymmetric of } \\
\text { information. } \\
\text { Possible impact: Likely to reduce overall }\end{array}$ \\
\hline $\begin{array}{c}\text { Asset resilience } \\
\text { affect cost capital in future. }\end{array}$ & $\begin{array}{l}\text { Some measures included in RIIO- } \\
1 .\end{array}$ & $\begin{array}{l}\text { Enhancement of previous measures } \\
\text { to further constrain companies' } \\
\text { ability to cut expenditure on asset } \\
\text { maintenance. }\end{array}$ & $\begin{array}{l}\text { Rationale: To ensure that the long-term } \\
\text { value to consumers is better reflected in } \\
\text { companies' business plan and that they are } \\
\text { held to account for delivery. }\end{array}$ \\
\hline $\begin{array}{c}\text { Return } \\
\text { adjustment } \\
\text { mechanisms }\end{array}$ & None. & $\begin{array}{l}\text { Considering company specific } \\
\text { sculpting for ET, GT and GD if } \\
\text { return deviate } \pm 3 \% .\end{array}$ & $\begin{array}{l}\text { Rationale: protect consumers against } \\
\text { excessive returns resulting from } \\
\text { information asymmetry faced by regulator } \\
\text { in setting revenues. Protecting investors } \\
\text { from downside risk. }\end{array}$ \\
$\begin{array}{c}\text { Possible impact: Might distort companies } \\
\text { incentives in terms of efforts to achieve } \\
\text { higher return and affect totex submission. }\end{array}$ \\
\hline
\end{tabular}

